\title{
QUEILOSCOPIA: CASO PERICIAL SIMULADO EMPREGANDO EVIDENCIAÇÃO COM PÓ DE GESSO TIPO IV
}

\section{CHEILOSCOPY: SIMULATED EXPERT CASE USING EVIDENCE WITH DENTAL STONE TYPE IV}

Bruna Pasquali Nogueira ${ }^{1}$, Lauren Volquind², Lucas Bozzetti Pigozzi ${ }^{3}$, Mariá Bellan ${ }^{4}$, Marília Paulus ${ }^{5}$, Alexandre Conde $^{6}$

\author{
Submetido: $13 / 12 / 2020$ \\ Aprovado: 25/01/2021
}

\section{RESUMO}

O estudo queiloscópico é uma ferramenta utilizada no campo da Odontologia legal, cujo seu objetivo é analisar, registrar e classificar as características labiais humanas. São características únicas de cada ser humano, que permanecem imutáveis ao longo da vida. O presente trabalho objetivou o emprego do Gesso Tipo IV para revelação da impressão labial de paciente voluntário. Um paciente da clínica Odontológica da FSG Centro Universitário, foi convidado a participar desta pesquisa, assinando o Termo de Consentimento Livre e Esclarecido (TCLE). Os lábios do voluntário foram fotografados e pressionados contra uma taça de plástico negra. Em seguida, depositamos o Gesso Tipo IV sobre a superfície desta taça. A impressão labial foi fixada, por meio de uma fita adesiva transparente na ficha queiloscópica adaptada de Stamm (2014). O confronto foi realizado com a fotografia dos lábios do paciente e a fotografia da impressão evidenciada, foi possível identificar 35 pontos coincidentes entre as duas imagens. O pó de Gesso Tipo IV depositado sobre a impressão labial latente obteve sucesso na evidenciação dela. Foi possível através da presente avaliação, concluir que o pó de Gesso Tipo IV depositado sobre uma impressão labial latente em substrato negro, foi capaz de tornar viável a sua evidenciação e passível de confronto queiloscópico.

PALAVRAS-CHAVE: Lábio. Odontologia Legal. Prova Pericial.

\begin{abstract}
The cheiloscopic study is a tool used in the field of forensic dentistry, whose objective is to analyze, record and classify human lip characteristics. They are unique characteristics of each human being, which remain unchanged through lifetime. The present study aims to use dental stone type IV to reveal the lip impression of a volunteer patient. The volunteer patient from the Dental Clinic of FSG Centro Universitário was invited to participate in this research by signing the informed consent form. The patient's lips were photographed and pressed against a black plastic cup. Then, the dental stone type IV was deposited on the surface of the cup. The lip impression was fixed by a transparent adhesive tape on the cheiloscopic sheet adapted from Stamm (2014). The confrontation was made with the photo of the patient's lips and with the photo of the evidence impression. It was possible to identify 35 matching points between the two images. The dental stone type IV powder deposited on the latent lip impression was successful in its disclosure. It was possible to conclude, through this
\end{abstract}

\footnotetext{
${ }^{1}$ Graduanda do Curso de Graduação em Odontologia - FSG Centro Universitário - Caxias do Sul/RS - ORCID: https://orcid.org/0000-0002-0389-0948

2 Graduanda do Curso de Graduação em Odontologia - FSG Centro Universitário - Caxias do Sul/RS - ORCID: https://orcid.org/0000-0002-5405-3752

3 Mestre em Prótese Dentária - Professor do Curso de Graduação em Odontologia - FSG Centro Universitário Caxias do Sul/RS - ORCID: https://orcid.org/0000-0003-0368-8149

${ }^{4}$ Mestre em Materiais Dentário- Professor do Curso de Graduação em Odontologia - FSG Centro Universitário Caxias do Sul/RS - ORCID: https://orcid.org/0000-0002-7074-3518

5 Doutora em Materiais Dentário- Professor do Curso de Graduação em Odontologia - FSG Centro Universitário - Caxias do Sul/RS - ORCID: https://orcid.org/0000-0002-2615-5284

6 Doutor em Materiais Dentários - Professor do Curso de Graduação em Odontologia - FSG Centro Universitário - Caxias do Sul/RS - ORCID: https://orcid.org/0000-0003-0224-2313
} 


\section{RECIMA21 - REVISTA CIENTÍFICA MULTIDISCIPLINAR}

QUEILOSCOPIA: CASO PERICIAL SIMULADO EMPREGANDO EVIDENCIAÇÃO

COM PÓ DE GESSO TIPO IV

Bruna Pasquali Nogueira, Lauren Volquind, Lucas Bozzetti Pigozzi, Mariá Bellan, Marília Paulus, Alexandre Conde

study that the dental stone type IV powder deposited on a latent lip impression on a black substrate was able to make its disclosure viable and susceptible to a cheiloscopic comparison.

KEYWORDS: Lip. Forensic Dentistry. Expert Testimony.

\section{INTRODUÇÃO}

A superfície que circunda a cavidade bucal, mais conhecida como mucosa labial, é rica em glândulas sebáceas e sudoríparas, que juntamente com a língua realizam a sua lubrificação, evidenciando o conjunto de linhas presentes ao longo da superfície labial. O estudo queiloscópico é responsável em analisar, registrar e classificar esse conjunto de linhas, auxiliando a justiça na resolução de casos de identificação tanto de vítimas quanto de criminosos. Em cenas criminais a impressão queiloscópica pode ser encontrada em diversos tipos de objetos e superfícies, como: travesseiros, copos, guardanapos, roupas, entre outros. ${ }^{1}$

A queiloscopia é uma das maneiras utilizadas no campo da Odontologia Legal, para identificar e diferenciar as características labiais humanas, é uma palavra de origem grega, "Cheilos" lábios e "Skopein" observe. Essas características labiais estão presentes no corpo humano desde o $42^{\circ}$ dia de vida intrauterina, e permanecem imutáveis ao longo da vida humana. ${ }^{2}$

A marca queiloscópica é uma característica exclusiva e imutável que cada ser humano possui e que dificilmente sofrerá alterações no decorrer da vida. Elas suportam diversos tipos de agressões, como as lesões herpéticas, que após sua cura retornam ao seu estado original, com exceção, de alguns ferimentos como, as queimaduras e cortes profundos, que deixam cicatrizes após sua cura. ${ }^{3}$

Essas características podem se apresentar de três formas: visíveis, latentes ou modeladas. As impressões visíveis são as que podem ser vistas a olho nu, geralmente reveladas imediatamente e apresentadas como manchas no contato com o sangue, tintas, batons e outros. As impressões latentes são as que o investigador necessita do auxílio de agentes reveladores para vê-las. E as impressões modeladas, são aquelas deixadas em superfícies maleáveis, como a manteiga, o chocolate, a cera e outros. ${ }^{4}$

Para evidenciar as impressões labiais latentes, os peritos geralmente fazem uso dos pós reveladores, estes são agrupados como brancos, negros, cinzas e magnéticos. De modo geral, o pó negro (sendo o pó negro-de-fumo considerado um revelador universal) e o pó cinza são aplicados em superfícies de cores claras, sendo pó negro dividido em diversos grupos como: grafite em pó, pó oxido de ferro e o pó de manganês. Já o pó branco (carbonato de chumbo) é aplicado em superfícies escuras, resultando em um contraste que deixará a impressão visível a olho nu. ${ }^{5}$

A ninidrina é um tipo de revelador químico muito eficaz, simples de usar e que apresenta resultados acelerados. Atua reagindo com os aminoácidos existentes nas impressões, podendo ser 


\section{RECIMA21 - REVISTA CIENTÍFICA MULTIDISCIPLINAR}

QUEILOSCOPIA: CASO PERICIAL SIMULADO EMPREGANDO EVIDENCIAÇÃO COM PÓ DE GESSO TIPO IV

Bruna Pasquali Nogueira, Lauren Volquind, Lucas Bozzetti Pigozzi, Mariá Bellan, Marília Paulus, Alexandre Conde

usado em todas as superfícies porosas e impressões contaminadas com sangue. Uma característica curiosa deste material, é que, a impressão que manteve contato com a mesma, se destruirá, o que seria uma desvantagem. Dentro dos reveladores Fluorescentes encontramos a diazafluorenona (DFO), que atua semelhantemente como a ninidrina, no entanto, não destrói a impressão após contato com a mesma. ${ }^{5}$

É muito importante que o examinador das impressões queiloscópicas passe por um processo de calibração antes de analisar as mesmas, já que existem diversas classificações para analisar as linhas labiais e estas se apresentam em grande quantidade em toda extensão labial. Outro fato importante, é de padronizar a classificação deste estudo como é feito na dactiloscopia, para que assim a análise queiloscópica obtenha resultados cada vez mais fidedignos. ${ }^{6}$

Entre as diversas classificações existentes na literatura, a proposta por Suzuki e Tsuchihashi (1971) é a mais citada e utilizada, isso por que é uma classificação de fácil entendimento e interpretação. Esses autores relataram em seu estudo o fato das impressões labiais serem únicas e de que alguns traços delas apresentam semelhanças hereditárias. ${ }^{7}$

Assim, por meio deste relato de caso, o presente trabalho tem por objetivo avaliar se o pó de Gesso Tipo IV é capaz de evidenciar as impressões labiais latentes.

\section{REFERENCIAL TEÓRICO}

\subsection{0 que é Queiloscopia}

A queiloscopia é uma palavra de origem grega onde "Cheilos" significa lábios e "Skopein", marcas, e é responsável pelo registro e análise das impressões labiais, como também, classificação das características labiais presentes na mesma. As linhas e ranhuras labiais são umas das peculiaridades existentes nos lábios, estas são únicas, permanentes e imutáveis ao longo de toda a vida. $^{2}$

A impressão queiloscópica se faz presente desde o iníci2o da vida, e permanece até mesmo em cenários post mortem, podendo sofrer alterações caso houver alguma patologia e/ou lesões que deixem cicatrizes. Muitos pesquisadores associam a importância do estudo queiloscópico com o dactiloscópico e apoiam que haja uma padronização da técnica, facilitando assim sua execução e tornando-o uma linguagem universal entre os profissionais. ${ }^{8}$

A queiloscopia é considerada uma técnica competente para pesquisa e singularização de indivíduos pela ciência criminal, no entanto, não apresenta um método padrão para análise das características, como também um número mínimo de pontos coincidentes entre a impressões queiloscópica e a fotografia labial do investigado. Alguns autores seguem o padrão de análise de 12 


\section{RECIMA21 - REVISTA CIENTÍFICA MULTIDISCIPLINAR}

QUEILOSCOPIA: CASO PERICIAL SIMULADO EMPREGANDO EVIDENCIAÇÃO

COM PÓ DE GESSO TIPO IV

Bruna Pasquali Nogueira, Lauren Volquind, Lucas Bozzetti Pigozzi, Mariá Bellan, Marília Paulus, Alexandre Conde

pontos iguais, baseando-se no estudo dactiloscópico, fazendo com que os resultados positivos obtidos no estudo queiloscópico se tornem mais fiéis e aceitáveis. ${ }^{9}$

As impressões queiloscópicas podem ser encontradas na forma visível, moldada ou latente, sendo a última, a mais difícil de ser localizada a olho nu, necessitando muitas vezes de agentes reveladores para evidenciá-las. As impressões labiais visíveis podem ser encontradas facilmente e geralmente são evidenciadas por cosméticos labiais utilizados pelo indivíduo, já as impressões modeladas são as localizadas em superfícies macias, como o chocolate e a manteiga. ${ }^{10}$

Quando em uma cena criminal não são encontradas as impressões visíveis, que geralmente são formadas por batons, os peritos buscam as impressões latentes, estas são formadas principalmente pela lubrificação dos lábios por meio das glândulas sebáceas, glândulas salivares e pela língua, e podem ser encontradas em diversas superfícies como guardanapos, copos, cigarros, roupas, entre outros. $O$ estudo e a análise aprofundada dessas impressões, auxiliam a justiça no esclarecimento de crimes já que este método possui o poder de realizar a identificação humana. ${ }^{1}$

\subsection{Odontologia (Especialidade Odontologia Legal) e Ciência Forense}

A ciência forense por sua vez é uma área multidisciplinar com o objetivo de auxiliar em investigações da justiça civil e criminal, com foco voltado para confirmar ou descartar a autoria de um crime por algum indivíduo. O perito criminal, quando deparado com uma cena de crime, deve observar diversos aspectos, como por exemplo objetos fora do lugar, os quais podem evidenciar vestígios como impressões dactiloscópicas ou queiloscópicas, fios de cabelo e vestígios de material genético como sangue, sêmen e/ou quaisquer tipos de secreção corporal, que possam identificar o autor do crime. ${ }^{11}$

A Odontologia Legal está incorporada na área da Ciência Forense, constituída pela resolução CFO-185/93, que no artigo 54, determinando-a como uma especialidade na Odontologia, que tem como objetivo a pesquisa de fenômenos psíquicos, físicos, químicos e biológicos que podem atingir ou ter atingido o homem, vivo, morto ou ossada, e mesmo fragmentos ou vestígios, resultando lesões parciais ou totais reversíveis ou irreversíveis. Segundo o artigo 63 e 64 da resolução CFO - 63/2005, nomeada como "Consolidação das normas para procedimentos nos Conselhos de Odontologia", é regulamentada a atuação do Odonto-Legal restringindo-se à perícia, estudo e prova de acontecimentos ligados à sua especialidade, podendo ampliar-se às demais especialidades se for preciso. $^{12}$

O especialista pode trabalhar na identificação do indivíduo ante mortem e post mortem; em perícias na área do direito trabalhista, civil, criminal, administrativo; tanatologia forense; traumatologia; elaboração de laudos, autos e pareceres, entre muitas outros. O perito é o responsável na execução de análises técnicas no meio da sua área profissional para esclarecer fatos 


\section{RECIMA21 - REVISTA CIENTÍFICA MULTIDISCIPLINAR}

QUEILOSCOPIA: CASO PERICIAL SIMULADO EMPREGANDO EVIDENCIAÇÃO

COM PÓ DE GESSO TIPO IV

Bruna Pasquali Nogueira, Lauren Volquind, Lucas Bozzetti Pigozzi, Mariá Bellan, Marília Paulus, Alexandre Conde

que posteriormente serão conteúdos de inquéritos policiais ou processos judiciais, contudo, sua atuação é restrita pois o mesmo não realiza julgamentos, acusações ou defesa do investigado. A responsabilidade do perito baseia-se exclusivamente em investigar e exibir acontecimentos fundamentais para elucidar um processo. ${ }^{13}$

Para realizar a identificação de um indivíduo existem muitos métodos, os exames realizados através do DNA são os mais utilizados e apresentam bons resultados, no entanto, este necessita de uma tecnologia específica e isso acaba tornando o trabalho mais demorado quando comparamos com os exames realizados através dos Odontolegistas. A Odontologia Legal é um recurso muito competente, protegido, leal, rápido, de baixa densidade tecnológica, eficazes e fundamentados cientificamente. O sucesso dos resultados dos exames obtidos por estes profissionais, é ocorrido, devido ao livre acesso a ficha odontológica, onde o profissional usa os dados encontrados nela para realizar comparações. ${ }^{14}$

A ficha odontológica é a principal ferramenta utilizada pelos Odontolegistas, pois apresenta diversos dados do indivíduo a ser identificado, estes dados são analisados principalmente por métodos comparativos. Segundo o Código de Ética Odontológico, o cirurgião-dentista possui a responsabilidade de completar adequadamente o prontuário odontológico, bem como de manter este atualizado e devidamente guardado. ${ }^{15}$

No prontuário odontológico podemos encontrar radiografias, fotografias, odontogramas, modelos de gesso como também registros queiloscópico, todos estes dados auxiliam os Odontolegistas nas suas investigações. Por este e muitos outros motivos é de grande importância processual que o profissional odontólogo responsável pelo investigado, guarde e zele pelos documentos e registros odontológicos deixados pelo mesmo em seu consultório, já que muitas vezes servem para realizar o fechamento de casos judiciais. ${ }^{16}$

\subsection{Casos criminais onde a Queiloscopia foi empregada}

No estudo de Fonseca et al., (2018) foram relatados dois casos criminosos, onde estes utilizaram o exame queiloscópico como ferramenta para a identificação dos criminosos, o que auxiliou a justiça na elucidação de ambos os casos. O primeiro caso ocorreu no ano de 1945 na cidade de Los Angeles, onde uma jovem havia sido atropelada por um carro e o condutor não prestou socorro, no entanto, as marcas queiloscópicas da vítima ficaram gravadas no para-choque do automóvel, fazendo com que o autor do crime fosse identificado e devidamente punido. Já o segundo caso ocorreu em 1979 na cidade de San Diego, onde uma jovem afro-americana realizou um assalto a banco e no momento da fuga a meliante bateu-se com o rosto na porta de vidro, deixando suas marcas labiais visíveis na mesma, já que esta utilizava batom no momento do ato criminoso. ${ }^{17}$ 


\section{RECIMA21 - REVISTA CIENTÍFICA MULTIDISCIPLINAR}

QUEILOSCOPIA: CASO PERICIAL SIMULADO EMPREGANDO EVIDENCIAÇ̃̃O

COM PÓ DE GESSO TIPO IV

Bruna Pasquali Nogueira, Lauren Volquind, Lucas Bozzetti Pigozzi, Mariá Bellan, Marília Paulus, Alexandre Conde

\subsection{Mucosa labial}

Os lábios representam toda a parte externa da boca, composta por glândulas sebáceas, glândulas sudoríparas, músculos, membrana mucosa e pele, sendo divididos entre lábio mucoso e lábio cutâneo, quando o lábio mucoso e o cutâneo se unem, formam o cordão labial, característica frequentemente vista em pessoas da raça negra. No lábio mucoso, também chamado de zona de Klein ou vermelhão dos lábios, encontramos as linhas e sulcos labiais. ${ }^{4}$

A coloração vermelha dos lábios se dá devido ao tipo de epitélio que se encontra na região, epitélio queratinizado escamoso, onde ele é rico por numerosos capilares. O lábio superior se localiza na região inferior do nariz, possui na área da linha média o filtro subnasal, sendo este originado no septo nasal, onde seu término no lábio determina uma região arredondada chamada tubérculo labial, este segue lateralmente até o sulco nasolabial. No lábio inferior, encontramos na região da linha média um acidente anatômico denominado de mosca, onde ele é limitado pelo lábio cutâneo e pelo o mento. Ambos os lábios estão unidos por meio das comissuras labiais. ${ }^{5}$

As glândulas sudoríparas e sebáceas que se encontram em torno dos lábios liberam secreções oleosas que, simultaneamente com a lubrificação provocada pelas glândulas salivares menores e a língua, geram as impressões labiais invisíveis. É a partir do $42^{\circ}$ dia de vida intrauterina, que os sulcos e as características labiais começam a tomar forma. Nesse momento a distribuição das características labiais permanecem imutáveis, resistindo a lesões físicas, inflamações e até mesmo lesões herpéticas, onde após a cura da mesma os lábios retornam a sua forma primária. Contudo, em grandes traumas, como em casos de queimaduras, cortes que afetam camadas mais profundas da pele e patologias mais graves como lábio leporino, podem ocorrer alterações labiais permanentes, dificultando o estudo queiloscópico. ${ }^{5}$

\subsection{Classificações queiloscópicas}

O estudo queiloscópico ainda não apresenta um único método de classificação das características presentes nos lábios, sendo esta uma das maiores dificuldades dentro das pesquisas queiloscópicas. No entanto, em todas as classificações encontradas na literatura, os lábios são separados em subquadrantes, sendo encontrado um grupo de linha prevalente em cada um destes. ${ }^{18}$

Apesar de não possuírem um padrão de classificação para as suas características, o estudo queiloscópico corresponde com os padrões teóricos (praticabilidade e classificabilidade) e biológicos (unicidade, perenidade e imutabilidade), tornando-se assim um método adotado para se realizar a identificação humana. Dentro da literatura encontramos mais de cinco modos diferentes de classificar (Classificação de Santos (1967), classificação de Suzuki e Tsuchihashi (1971), classificação de 


\section{RECIMA21 - REVISTA CIENTÍFICA MULTIDISCIPLINAR}

QUEILOSCOPIA: CASO PERICIAL SIMULADO EMPREGANDO EVIDENCIAÇÃO COM PÓ DE GESSO TIPO IV

Bruna Pasquali Nogueira, Lauren Volquind, Lucas Bozzetti Pigozzi, Mariá Bellan, Marília Paulus, Alexandre Conde

Renaud (1973), classificação de Dominguez, Romero e Capilla (1975), classificação de Afchar-Bayat (1978) e a classificação de Oviedo (1988).) as linhas e ranhuras presentes na mucosa labial. ${ }^{19}$

Todavia a classificação mais utilizada pelos profissionais forenses é a de Suzuki e Tsuchihashi (1971), já que esta apresenta uma linguagem de fácil entendimento e clareza, sendo os símbolos dispostos em algarismos romanos e divididos em seis grupos. Grupo I - Linha Vertical Completa (sulcos retos e bem definidos que correm verticalmente através do lábio e cobrem toda a sua extensão); Grupo l' - Linha vertical Incompleta (sulcos retos que desaparecem, porém, no meio do curso, sem cobrir a extensão de todo o lábio); Grupo II - Linhas ramificadas ou bifurcadas (os sulcos se bifurcam ao longo de seu trajeto); Grupo III - Linha Entrecruzada (sulcos que se entrecruzam em forma de aspas ou em "X“); Grupo IV - Linha Reticular (produzem múltiplas cruzes que geram aspecto de um retículo ou malha); Grupo V - Linha com padrão irregular (consideradas linhas em outras formas) ${ }^{7}$

O lábio superior e o inferior são unidos pelas comissuras labiais e se apresentam em diferentes espessuras, as quais também são classificadas em grupos diferentes, são estes: Lábios finos/delgados (quando a mucosa labial é pouco visível, menos de $8 \mathrm{~mm}$ ), médios (espessura de 8 a $10 \mathrm{~mm}$ ), grossos (espessura superior a $10 \mathrm{~mm}$ ) ou mistos. Quando observamos as comissuras labiais, podemos classificá-las conforme a sua posição como elevadas, horizontais ou abaixadas, em relação a linha perpendicular à linha média labial. ${ }^{6} \mathrm{Com}$ o avanço da idade o terço inferior da face pode sofrer algumas alterações, sendo a espessura labial e as comissuras labiais as mais afetadas devido à perda da tonicidade muscular, no entanto estas características são consideradas auxiliadoras no estudo queiloscópico. ${ }^{20}$

Para serem classificadas, as impressões labiais são postas em uma ficha queiloscópica, onde o observador separa a ficha em duas partes, uma para a impressão labial do indivíduo e outra para a foto dos lábios. A impressão labial é dividida em 4 quadrantes, e após isto, são comparadas ambos e marcados todos os pontos coincidentes e classificados segundo a classificação escolhida. ${ }^{21}$

Os sulcos e linhas labiais podem se sobrepor na ficha queiloscópica, não existindo uma pessoa que apresente apenas um tipo de sulco em toda sua impressão queiloscópica. A mucosa labial apresenta muitos linhas e sulcos diferentes em sua superfície, isso exige que os examinadores possuam um treinamento prévio a análise das impressões queiloscópicas, sendo também necessário a enumeração dos sulcos encontrados seguindo a ordem de disposição na mucosa labial, em cada quadrante em questão. ${ }^{22}$

\subsection{0 armazenamento e os agentes reveladores das impressões labiais}

Com o desenvolvimento do estudo queiloscópico, alguns softwares foram desenvolvidos como o Queilosoft, para realizar o armazenamento dos dados queiloscópicos. Por meio destes 


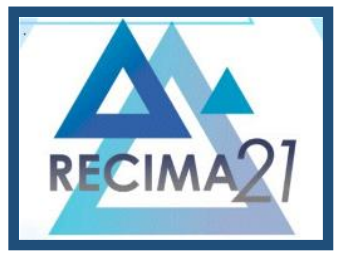

\section{RECIMA21 - REVISTA CIENTÍFICA MULTIDISCIPLINAR}

QUEILOSCOPIA: CASO PERICIAL SIMULADO EMPREGANDO EVIDENCIAÇÃO

COM PÓ DE GESSO TIPO IV

Bruna Pasquali Nogueira, Lauren Volquind, Lucas Bozzetti Pigozzi, Mariá Bellan, Marília Paulus, Alexandre Conde

softwares, a análise dos padrões labiais se tornou mais precisa, realizada em um menor tempo e com custo reduzido, mantendo as informações conservadas por meio do seu armazenamento digital. ${ }^{23}$

Alguns autores também testaram o método fraile para revelação e armazenamento das impressões queiloscópicas. Para realização desta técnica, os lábios devem estar limpos e após devem ser fotografados, aplica-se solução reveladora sobre a mucosa labial e abre-se um filme radiográfico virgem, sendo este velado, pressiona-se suavemente sobre os lábios em movimento de rolagem. Após este processo de coleta as imagens são submersas no fixador a 3\% durante 15 a 20 segundos, lavadas com água e secas. Em $95 \%$ dos casos os autores obtiveram sucesso na utilização deste método para realizar a visualização e posterior leitura e classificação das impressões labiais. ${ }^{24}$

As impressões queiloscópicas podem ser evidenciadas por meio dos seguintes pós reveladores: Metálico prateado, nitrato de prata, carbonato de prumo, corante de anilina preta gorda, óxido de cobalto, corante de lisocromos ou corantes fluorescentes. Para se obter uma boa impressão, esta dependerá da maneira que foi registrada e o substrato ao qual foi encontrada. ${ }^{25}$

Estas substâncias atuam por meio de técnicas físicas (ação mecânica por depósito; apresentam-se como pó, gás ou líquido) ou técnicas químicas (reação química ou molecular), para revelar as impressões que não se encontram visíveis a olho nu. Os reveladores físicos na forma de pó são os mais utilizados devido ao seu baixo custo e sua técnica ser de fácil e rápida execução. A fixação dos pós na impressão labial, se dá devido as substâncias presentes na mesma. Os pós se fixam na água e em elementos oleosos presentes na impressão labial, quando a impressão for coletada em um curto espaço de tempo, caso a impressão demore para ser coletada, o pó somente se fixará nos elementos oleosos da impressão. ${ }^{26,5}$

Os pós são agrupados como brancos, negros, cinzas e magnéticos. De modo geral, o pó negro e o pó cinza são aplicados em superfícies de cor azul, violeta, branca e claras, já o pó branco é aplicado em superfícies escuras, resultando em um contraste que deixará a impressão visível a olho nu. O pó negro-de-fumo é considerado um revelador universal e compõem-se de um pó fino e negro. Podendo este se dividir em diversos grupos, sendo ele grafite em pó, pó oxido de ferro e o pó de manganês. O carbonato de chumbo está dentro do grupo de pós brancos, que apresenta em sua composição o chumbo e por esta razão seu uso se torna criticado apesar de apresentar um custo reduzido. ${ }^{26,5}$

$\mathrm{Na}$ técnica com reveladores químicos podemos aplicá-los sobre superfícies rugosas e mais antigas onde as impressões não se encontram visíveis a olho nu, seu uso é indicado exclusivamente em madeiras não tratadas. A ninidrina é um composto muito eficaz, simples de usar e que apresenta resultados acelerados, pode ser usada em superfícies porosas e impressões contaminadas com 


\section{RECIMA21 - REVISTA CIENTÍFICA MULTIDISCIPLINAR}

QUEILOSCOPIA: CASO PERICIAL SIMULADO EMPREGANDO EVIDENCIAÇÃO

COM PÓ DE GESSO TIPO IV

Bruna Pasquali Nogueira, Lauren Volquind, Lucas Bozzetti Pigozzi, Mariá Bellan, Marília Paulus, Alexandre Conde

sangue. Uma característica curiosa deste material, é que, a impressão que manteve contato com a mesma, se destruirá, tornando assim juntamente com seu alto custo uma desvantagem. A diazafluorenona (DFO) atua semelhantemente como a ninidrina, porém está classificado dentre os pós fluorescentes, ela é um reagente muito eficiente por apresentar um contraste aumentado, podendo-se aplicar em superfícies porosas e em papel, o qual frente à radiação óptica expõe as impressões latentes. ${ }^{26,5}$

Segundo postado em literatura, os pós reveladores convencionais não possuem eficácia na revelação de impressões labiais mais antigas. O uso do Nilo Vermelho (um tipo de revelador fluorescente) sobre impressões latentes, mostrou boa efetividade. Já os pós magnéticos são utilizados para desenvolver marcas digitais, revelar marcas mais antigas encontradas em superfícies porosas, sendo mais visíveis no papel, e os pós de alumínio ficam mais destacados em superfícies escuras e espelhadas. ${ }^{3}$

\section{METODOLOGIA}

\subsection{Problema da pesquisa}

Hoje em dia existem diferentes tipos de pós reveladores entre outros materiais, que são utilizados para evidenciar impressões labiais latentes, viabilizando um confronto queiloscópico onde o profissional Odonto-Legal analisa cuidadosamente as linhas e sulcos presentes na impressão. $O$ pó de Gesso Tipo IV poderia ser utilizado para auxiliar a Odontologia Forense na evidenciação de impressões labiais latentes.

\subsection{Tipo de pesquisa}

É um relato de caso, qualitativo, descritivo de método comparativo pois envolve um confronto pericial. ${ }^{27}$ Este trabalho foi aprovado pelo Comitê de Ética em Pesquisa da FSG Centro Universitário sobre o parecer número 4.177.915 / CAAE 34261920.8.0000.5668. Para realização deste estudo foi selecionado um paciente que aceitou em participar do estudo sem nenhuma remuneração e custo financeiro, e que concordou em assinar o Termo de Consentimento Livre e Esclarecido (TCLE).

O paciente J.R.M.C, 30 anos, brasileiro, residente em Caxias do Sul-RS, selecionado para a presente pesquisa, compareceu ao Complexo Odontológico da FSG Centro Universitário no dia 06 


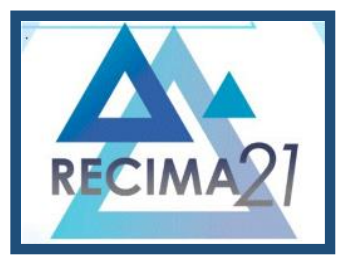

\section{RECIMA21 - REVISTA CIENTÍFICA MULTIDISCIPLINAR}

QUEILOSCOPIA: CASO PERICIAL SIMULADO EMPREGANDO EVIDENCIAÇ̃̃O COM PÓ DE GESSO TIPO IV

Bruna Pasquali Nogueira, Lauren Volquind, Lucas Bozzetti Pigozzi, Mariá Bellan, Marília Paulus, Alexandre Conde

de outubro de 2020 às $10 \mathrm{hs}$. A abordagem ao paciente foi realizada, seguida de explicações sobre 0 propósito do presente estudo.

Inicialmente, na abordagem experimental clínica, foram realizadas fotografias detalhadas dos lábios do paciente utilizando um smartphone com câmera fotográfica de 12Mp (IPhone 7, Apple, Califórnia, Estados Unidos da América), posteriormente, o paciente depositou sua impressão labial em uma taça de plástico negra (EOE plásticos, Caxias do Sul, Brasil) (Figura 1), obtendo-se uma impressão labial latente que foi fotografada (Figura 1). O paciente foi liberado em seguida.

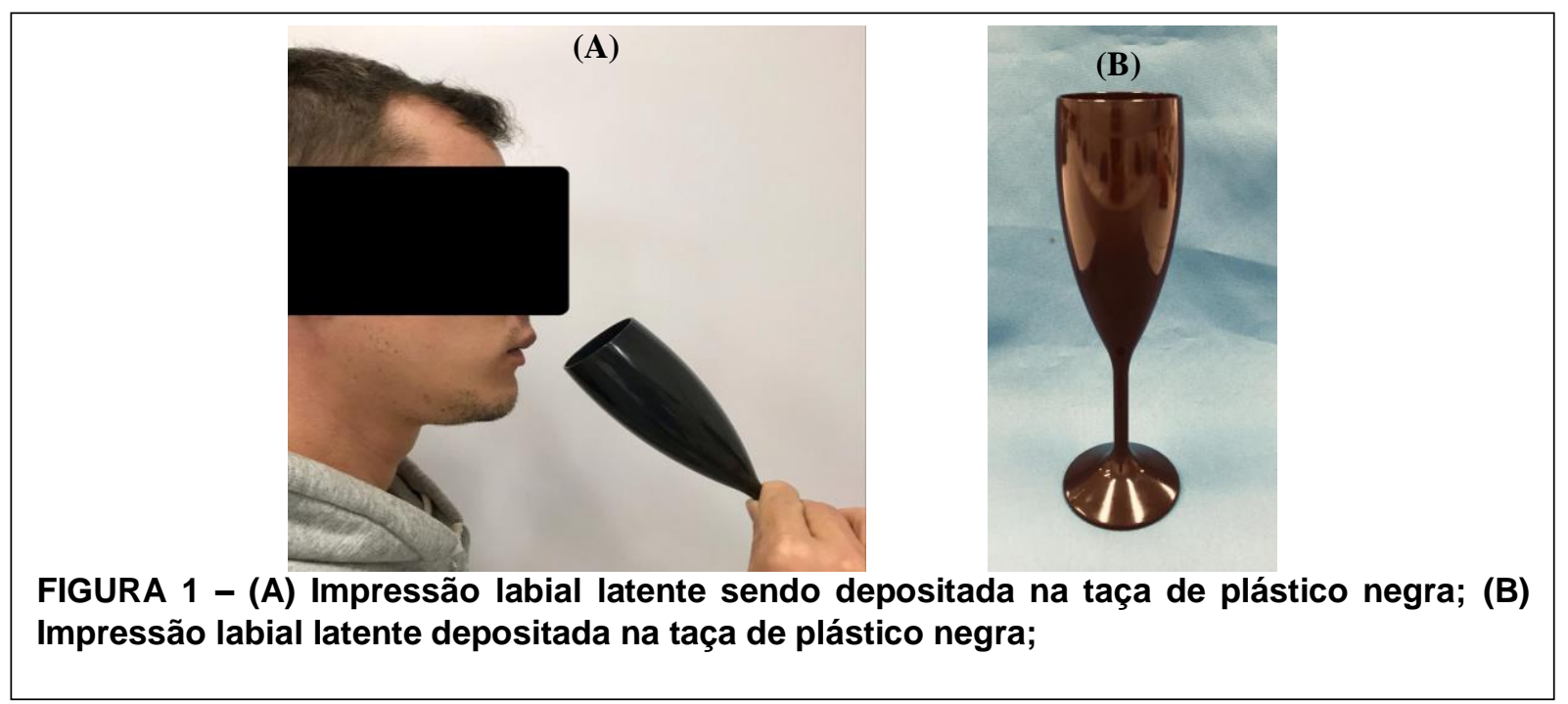

$\mathrm{Na}$ abordagem experimental laboratorial, foi depositado o pó de Gesso Pedra Especial Durone Tipo IV (Dentsply Sirona, Pirassununga, Brasil), sobre a impressão labial latente presente na taça, onde realizamos a fotografia deste procedimento (Figura 2). Com o pó depositado sobre a impressão na taça, deu-se um leve jato de ar a uma distância de $30 \mathrm{~cm}$ utilizando a seringa tríplice (Dabi Atlante, Ribeirão Preto - SP, Brasil) e fio ortodôntico duro elástico CrNi 0,70mm (MORELLI®, Sorocaba, SP - Brasil) como mantenedor de distância, para retirada de excessos do pó de Gesso Tipo IV. Em seguida foi realizada outra fotografia deste procedimento (Figura 2). O leve jato de ar lançado sobre o pó de Gesso Tipo IV ocorreu com pressão de aproximadamente 28 psi, medida pelo 


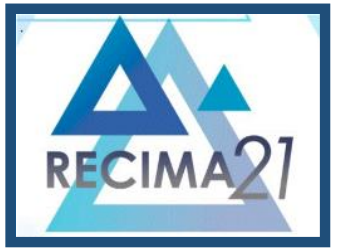

\section{RECIMA21 - REVISTA CIENTÍFICA MULTIDISCIPLINAR}

QUEILOSCOPIA: CASO PERICIAL SIMULADO EMPREGANDO EVIDENCIAÇÃO COM PÓ DE GESSO TIPO IV

Bruna Pasquali Nogueira, Lauren Volquind, Lucas Bozzetti Pigozzi, Mariá Bellan, Marília Paulus, Alexandre Conde

manômetro de aferição dos terminais do equipo (Dabi Atlante, Ribeirão Preto - SP, Brasil), assim, a impressão labial foi evidenciada sem excessos de pó de Gesso Tipo IV. Em seguida, realizamos a fotografia da taça com a impressão labial evidenciada, seguido da fixação da fita adesiva transparente (3M Scoth, Sumaré, Brasil) utilizando a sua parte colante pressionada sobre a impressão labial evidenciada (Figura 2) onde fixamos a mesma na ficha queiloscópica adaptada de STAMM, 2014 (Figura 3).
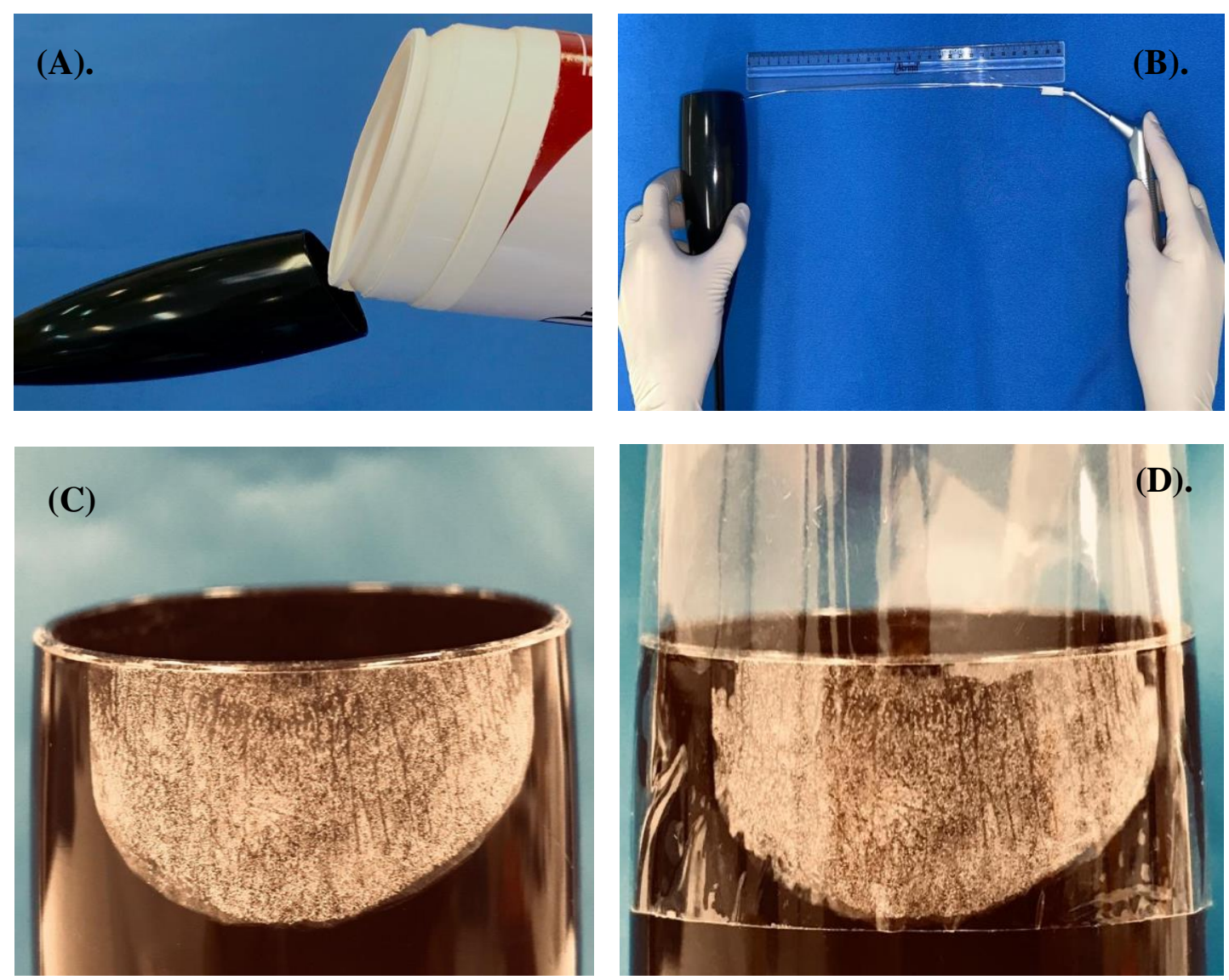

FIGURA 2 - (A). Deposição do pó de Gesso Tipo IV sobre a impressão labial latente; (B). Leve jato de ar a uma distância de $30 \mathrm{~cm}$; (C). Impressão labial revelada; (D). Fixação da fita adesiva $45 \mathrm{~mm}$ x $45 \mathrm{~mm}$ sobre a impressão labial revelada. 


\section{RECIMA21 - REVISTA CIENTÍFICA MULTIDISCIPLINAR}

QUEILOSCOPIA: CASO PERICIAL SIMULADO EMPREGANDO EVIDENCIAÇÃO COM PÓ DE GESSO TIPO IV Bruna Pasquali Nogueira, Lauren Volquind, Lucas Bozzetti Pigozzi, Mariá Bellan, Marília Paulus, Alexandre Conde

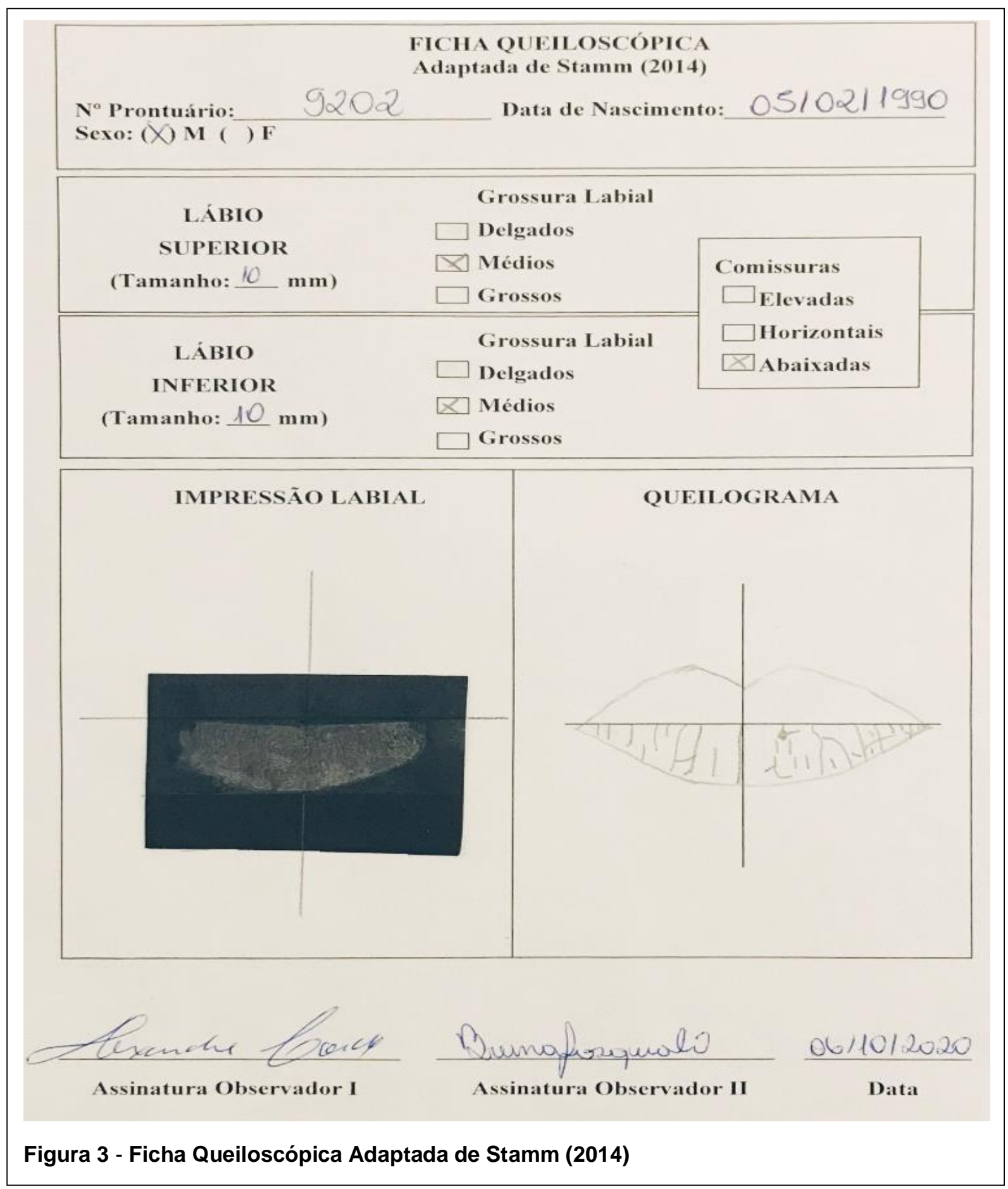

\subsection{Justificativa}

No estudo de Barros e Silva (2006), os autores apresentam vários materiais empregados para a realização da revelação de impressões labiais latentes, no entanto, não relatam sobre o uso 


\section{RECIMA21 - REVISTA CIENTÍFICA MULTIDISCIPLINAR}

QUEILOSCOPIA: CASO PERICIAL SIMULADO EMPREGANDO EVIDENCIAÇ̃̃O COM PÓ DE GESSO TIPO IV

Bruna Pasquali Nogueira, Lauren Volquind, Lucas Bozzetti Pigozzi, Mariá Bellan, Marília Paulus, Alexandre Conde

do gesso tipo IV. O conhecimento adquirido por meio desta pesquisa pode contribuir positivamente para a leitura identificando a viabilidade do emprego deste material com o propósito de evidenciação de impressões labiais latentes. ${ }^{5}$

\section{RESULTADOS E DISCUSSÃO}

Após a realização dos procedimentos laboratoriais, foi realizada a classificação da impressão labial evidenciada através do método de Suzuki e Tsuchihashi (1971) (Tabela 1) e confronto entre a foto da impressão labial revelada com a foto dos lábios do paciente no software incluso no sistema operacional Windows, Microsoft Paint (Microsoft Corporation, Redmond, Washington, Estados Unidos) presente no sistema operacional Windows. A identificação das linhas coincidentes foi realizada com a ferramenta de pintura do programa Paint, utilizando as cores azul, vermelha, preta e verde para facilitar a identificação dos sulcos. Com um minucioso confronto queiloscópico foi possível observar 35 pontos coincidentes entre as duas fotografias (Figuras 4 a 6 ).

Tabela 1. Classificação de Suzuki y Tsuchihashi (1971) e resultados encontrados no confronto queiloscópico

\begin{tabular}{|c|c|c|c|}
\hline Tipos de sulcos labiais & $\begin{array}{l}\text { Características dos tipos } \\
\text { de sulcos labiais }\end{array}$ & $\begin{array}{l}\text { Forma dos } \\
\text { sulcos } \\
\text { labiais }\end{array}$ & $\begin{array}{l}\text { № de sulcos } \\
\text { coincidentes } \\
\text { encontrados }\end{array}$ \\
\hline $\begin{array}{l}\text { Tipo I } \\
\text { (Linhas verticais completas) }\end{array}$ & $\begin{array}{l}\text { Sulcos retos e bem } \\
\text { definidos que correm } \\
\text { verticalmente pelo lábio e } \\
\text { cobrem toda a sua } \\
\text { extensão. }\end{array}$ & & 02 \\
\hline $\begin{array}{l}\text { Tipo l' } \\
\text { (Linhas verticais incompletas) }\end{array}$ & $\begin{array}{l}\text { Sulcos retos, que } \\
\text { desaparecem, porém, no } \\
\text { meio do curso, sem cobrir a } \\
\text { extensão de todo o lábio. }\end{array}$ & & 21 \\
\hline $\begin{array}{l}\text { Tipo II } \\
\text { (Linhas Ramificadas ou } \\
\text { Bifurcadas) }\end{array}$ & $\begin{array}{l}\text { Sulcos que se entrecruzam } \\
\text { em forma de aspas ou de } \\
\text { "X". }\end{array}$ & & 01 \\
\hline $\begin{array}{l}\text { Tipo V } \\
\text { (Linhas em outras formas) }\end{array}$ & $\begin{array}{l}\text { Sulcos em formas que não } \\
\text { se enquadram em } \\
\text { nenhuma das } \\
\text { classificações anteriores. }\end{array}$ & & 11 \\
\hline
\end{tabular}




\section{RECIMA21 - REVISTA CIENTÍFICA MULTIDISCIPLINAR}

QUEILOSCOPIA: CASO PERICIAL SIMULADO EMPREGANDO EVIDENCIAÇ̃̃O COM PÓ DE GESSO TIPO IV Bruna Pasquali Nogueira, Lauren Volquind, Lucas Bozzetti Pigozzi, Mariá Bellan, Marília Paulus, Alexandre Conde

\section{Total de sulcos coincidentes encontrados}
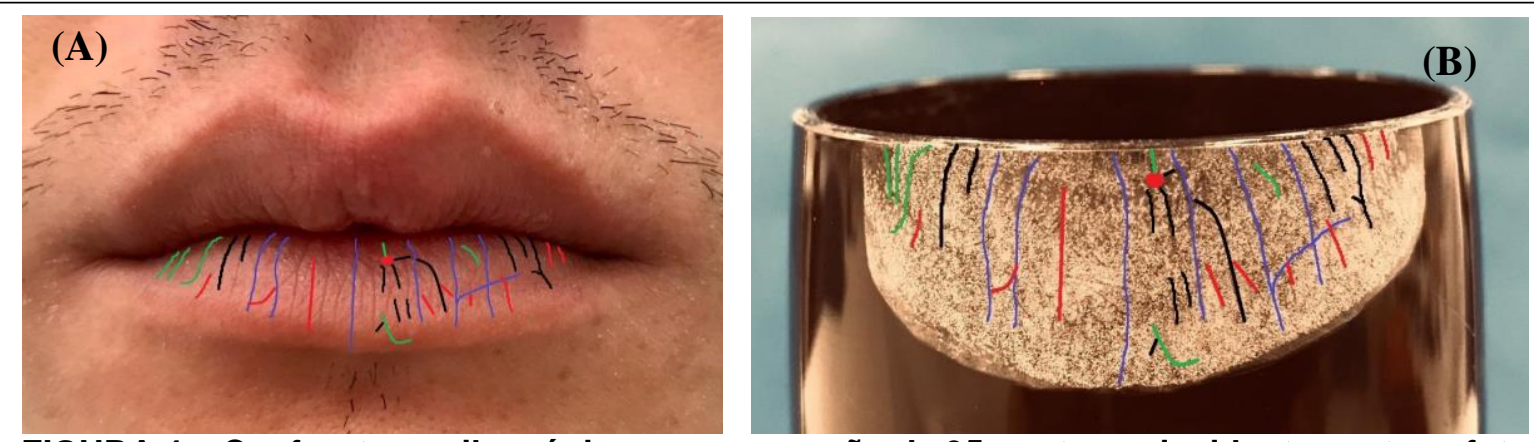

FIGURA 4 - Confronto queiloscópico com marcação de 35 pontos coincidentes entre a foto dos lábios do paciente (A) e a foto da impressão labial revelada (B).
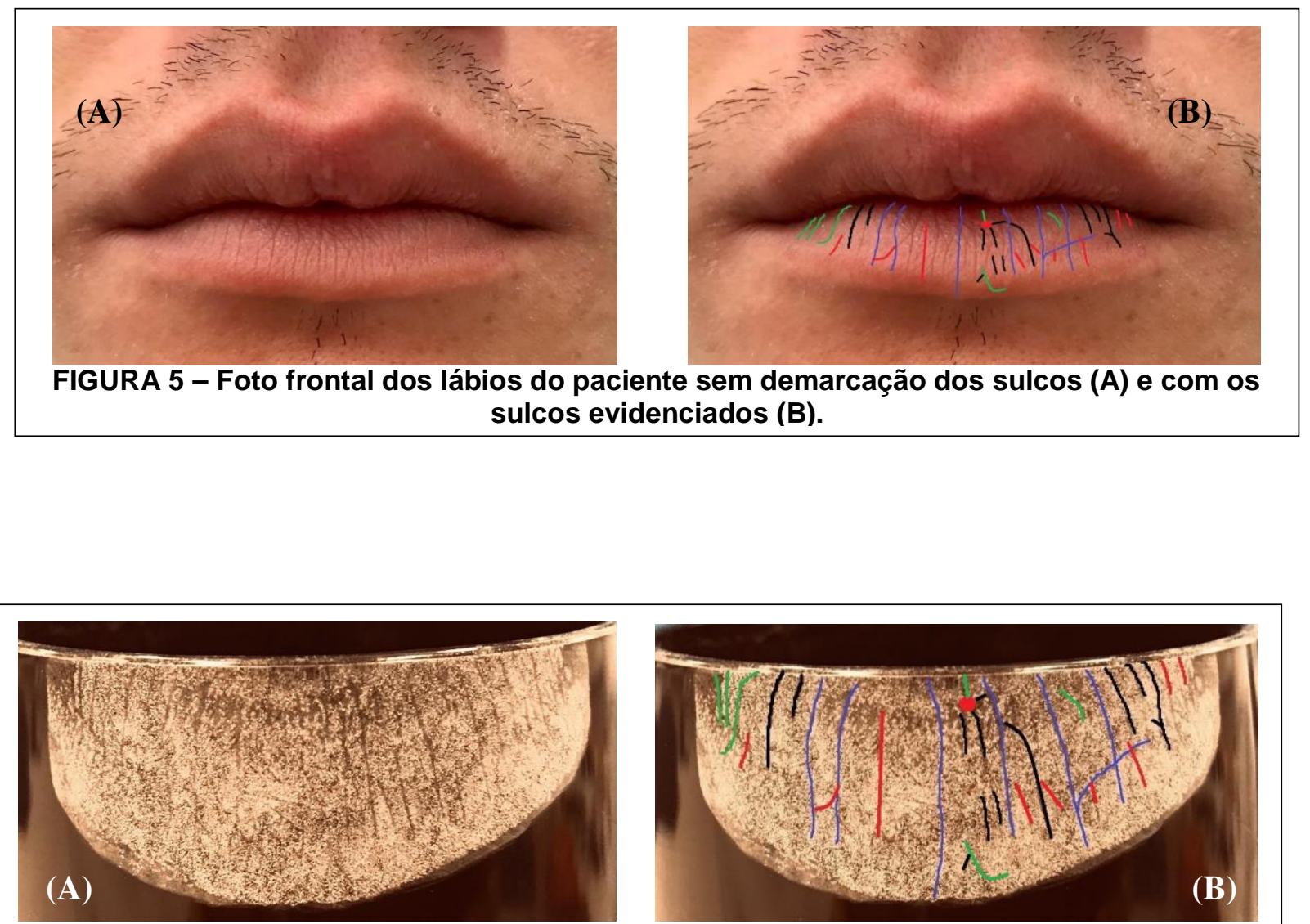

FIGURA 6 - (A) Impressão labial revelada; (B) Impressão labial revelada com a evidenciação dos sulcos. 


\section{RECIMA21 - REVISTA CIENTÍFICA MULTIDISCIPLINAR}

QUEILOSCOPIA: CASO PERICIAL SIMULADO EMPREGANDO EVIDENCIAÇÃO COM PÓ DE GESSO TIPO IV Bruna Pasquali Nogueira, Lauren Volquind, Lucas Bozzetti Pigozzi, Mariá Bellan, Marília Paulus, Alexandre Conde

Para registro documental foi utilizada a ficha queiloscópica adaptada de STAMM, 2014. Foi identificado que a paciente possui, de acordo com a classificação de Suzuki e Tsushihashi (1971), 2 sulcos do tipo I (Sulco vertical completo), 21 sulcos do tipo I' (Sulcos verticais incompletos), 1 sulco do tipo II (linhas ramificadas ou bifurcadas), nenhum sulco do tipo III (Sulcos entrecruzados) e tipo IV (Sulcos reticulados), 11 sulcos do tipo $\mathrm{V}$ (Sulcos de outro padrão), (Gráfico 1). O lábio superior foi classificado como médio, já que apresenta $10 \mathrm{~mm}$ de espessura, assim como, o lábio inferior, que também apresenta $10 \mathrm{~mm}$ de espessura. As comissuras labiais do paciente foram classificadas como abaixadas, já que se apresentam abaixo da linha perpendicular à linha média labial. ${ }^{5,6,28}$ Todas estas informações foram registradas na ficha queiloscópica, sendo devidamente assinada por ambos os pesquisadores.

Segundo o método de classificação de Suzuki e Tsushihashi (1971), para realizarmos o confronto queiloscópico devemos dividir a impressão em quatro quadrantes, para então registrarmos

\section{GRÁFICO 1 - RESULTADO DO NÚMERO DE SULCOS COINCIDENTES ENCONTRADOS NO CONFRONTO QUEILOSCÓPICO}

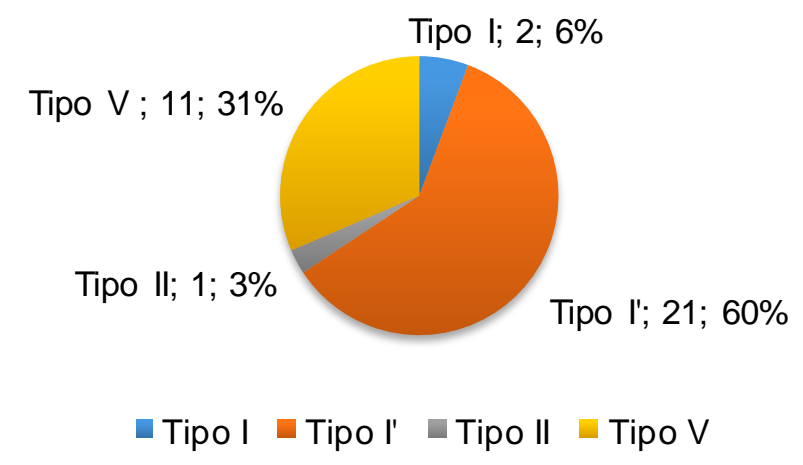

o tipo de sulco que aparece com maior frequência em cada um desses quadrantes, na ficha queiloscópica. ${ }^{7,26,28}$

Para obtermos uma classificação completa e adequada devemos analisar também a disposição das comissuras labiais em relação a linha perpendicular à linha média labial (elevadas, horizontais ou abaixadas) e a espessura de ambos os lábios finos ou delgados com menos de $8 \mathrm{~mm}$ (maior predominância na raça caucasiana); médios entre 8 a $10 \mathrm{~mm}$ (mais frequente na população em geral); grossos ou muito grossos com mais de $10 \mathrm{~mm}$ (maior predominância na raça negroide) ${ }^{5,6,28}$

Alguns estudos queiloscópicos determinam um número mínimo de 12 pontos coincidentes entre a imagem do lábio do pesquisado e a imagem da impressão labial evidenciada, baseando-se 


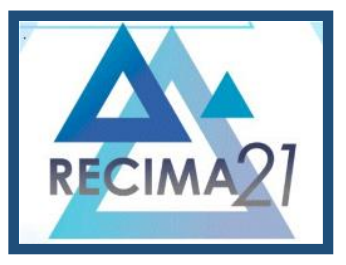

\section{RECIMA21 - REVISTA CIENTÍFICA MULTIDISCIPLINAR}

QUEILOSCOPIA: CASO PERICIAL SIMULADO EMPREGANDO EVIDENCIAÇÃO

COM PÓ DE GESSO TIPO IV

Bruna Pasquali Nogueira, Lauren Volquind, Lucas Bozzetti Pigozzi, Mariá Bellan, Marília Paulus, Alexandre Conde

no estudo dactiloscópico, já que o estudo queiloscópico não possui um número mínimo de pontos coincidentes entre as duas imagens para considerarmos se o resultado encontrado é positivo ou negativo. 5,9,21,26 Baseando-se neste ponto, podemos afirmar que o resultado obtido com o método utilizado por este estudo é positivo, já que foram encontrados 35 pontos coincidentes entre as duas imagens registradas.

Apesar de existir o programa de computador Queilosoft (matlab), onde conseguimos realizar o confronto queiloscópico digitalmente, analisar as imagens de maneira mais clara e precisa, podendo armazenar todos os dados dentro de um sistema, evitando o risco de perda destes e viabilizando novas comparações em momentos futuros ${ }^{8,21}$, o confronto do presente estudo foi realizado por comparação direta, onde colocamos as duas imagens lado a lado, enumerando os pontos coincidentes e marcando-os com as cores azul, vermelho, verde e preto, utilizando as ferramentas presentes no Microsoft Paint.

No momento do confronto queiloscópico foi possível notar alguns traços com uma diferença mínima de distância entre eles, como também, a sobreposição dos mesmos quando comparadas as duas fotografias (dos lábios do paciente e da impressão labial evidenciada). ${ }^{18,20}$ No entanto este fato, era esperado já que o método escolhido para coleta da impressão foi o movimento de rolagem, que acaba contribuindo para a redução de tamanho dos sulcos e a distância diferente entre eles, isso devido à pressão depositada sobre os lábios no momento da coleta, fazendo com que o músculo orbicular dos lábios fique contraído ao invés de relaxado como no momento da fotografia dos lábios. ${ }^{18,20,26}$ Para aumentar a precisão do confronto queiloscópico, sugere-se que no momento da análise queiloscópica dividamos a em quadrantes (diminuindo assim, os erros devido a sobreposição dos sulcos e viabilizando a obtenção de mais detalhes queiloscópicos), como também, que tenhamos mais de um profissional treinado com embasamento teórico para efetuar esta análise minuciosamente. ${ }^{28}$

Para a realização de um confronto queiloscópico, o registro fotográfico é um fator muito importante, sendo a máquina fotográfica de uso profissional a mais indicada, isso porque, ela possibilita que o profissional realize ajustes manualmente resultando em imagens mais fidedignas e com maior precisão, assim como, a utilização da técnica digital que baseia-se na sobreposição através de aplicativos de software que proporcionam melhorias nas imagens obtidas, auxiliando os Odontolegistas durante a análise do confronto, ao invés do método convencional utilizado no presente estudo, que baseia-se na comparação da marca deixada na taça de plástico negra, com as do lábios do paciente. ${ }^{3,26} \mathrm{Na}$ presente pesquisa o fato de utilizarmos a câmera do telefone celular, trouxe algumas desvantagens como alguns pontos com reflexos e sombras, o que acabou dificultando o confronto queiloscópico entre as duas imagens. No entanto foi optado em utilizar esta 


\section{RECIMA21 - REVISTA CIENTÍFICA MULTIDISCIPLINAR}

QUEILOSCOPIA: CASO PERICIAL SIMULADO EMPREGANDO EVIDENCIAÇÃO

COM PÓ DE GESSO TIPO IV

Bruna Pasquali Nogueira, Lauren Volquind, Lucas Bozzetti Pigozzi, Mariá Bellan, Marília Paulus, Alexandre Conde

ferramenta devido ao seu fácil acesso e por apresentar um baixo custo quando comparada com uma máquina fotográfica profissional.

Na extensão do vermelhão dos lábios encontram-se glândulas sebáceas e glândulas sudoríparas, que juntamente com a saliva realizam a lubrificação deles, e que quando em contato com alguma superfície estas secreções acabam formando uma impressão labial latente, que posteriormente será evidenciada com o auxílio de agentes reveladores, normalmente os em forma de pó. Quando a impressão labial latente for recente, as partículas deste pó iram se unir as partículas oleosas e aquosas presentes na mesma, e caso esta for mais antiga, as partículas do pó se uniram somente as partículas oleosas presentes na impressão. ${ }^{5,26}$ No caso da presente pesquisa, as partículas do pó de Gesso Tipo IV se uniram tanto as partículas oleosas, quanto nas partículas aquosas, isso porque, logo após que o paciente deixou a sua impressão labial latente na taça, depositou-se o pó de Gesso Tipo IV sobre a impressão, realizando a evidenciação dela.

Os agentes reveladores em forma de pó fazem parte da técnica física, onde a evidenciação ocorre por meio da ação mecânica por depósito, nesta técnica além do pó, também podemos encontrar esses agentes na forma de gás ou líquido. Os pós podem ser divididos em brancos (aplicados principalmente em superfícies escuras), negros e cinzas (aplicados principalmente em superfícies claras) e os pós magnéticos. Em grande maioria dos casos, os pesquisadores optam em utilizar os agentes reveladores em forma de pó devido ao seu fácil manuseio e menor custo. ${ }^{5,26}$ No referente estudo optou-se em utilizar o Gesso Tipo IV, devido ao fato de não possuírem estudo utilizando o mesmo, como também, por ser um material de fácil manuseio e custo acessível.

Pelo fato desta pesquisa ser efetuada pelo método comparativo, devemos nos preocupar principalmente com a obtenção do maior número de informações e características do paciente e não somente com a coleta da impressão labial, evidenciação, fixação e conservação da mesma, já que essas características labiais, assim como as dactiloscópicas, são únicas em cada indivíduo, o que viabiliza a identificação e singularização dos mesmos, auxiliando a justiça na elucidação de casos criminais e diminuindo assim a impunidade de algum ato criminoso. $5,8,13,20,26$

De maneira geral, a coleta de uma impressão labial latente, do mesmo modo que foi realizada na presente pesquisa, é efetuada por meio de um agente revelador, seguido da fixação de uma fita adesiva transparente sobre a evidencia, utilizando uma força leve, e após isso, a transferência da mesma para uma folha de papel em branco, no nosso caso a ficha queiloscópica, evitando distorções e até mesmo a perca da mesma. ${ }^{19,26}$ No entanto, sabe-se que quando a impressão é coletada de maneira direta, diretamente dos lábios do pesquisado, as chances de ocorrerem distorções e sobreposições dos sulcos são menores, o que facilita um posterior confronto e classificação da mesma. ${ }^{28}$ 


\section{RECIMA21 - REVISTA CIENTÍFICA MULTIDISCIPLINAR}

QUEILOSCOPIA: CASO PERICIAL SIMULADO EMPREGANDO EVIDENCIAÇÃO

COM PÓ DE GESSO TIPO IV

Bruna Pasquali Nogueira, Lauren Volquind, Lucas Bozzetti Pigozzi, Mariá Bellan, Marília Paulus, Alexandre Conde

Existem muitos agentes reveladores disponíveis para realizar a evidenciação de impressões labiais latentes, no entanto, o Gesso Tipo IV utilizado em nosso trabalho, ainda não havia sido testado ou citado para este fim. O conhecimento adquirido por meio deste estudo contribui positivamente para a literatura identificando a viabilidade do emprego deste material com o propósito de evidenciação de impressões labiais latentes. ${ }^{5}$ Todavia, mais estudos se fazem necessário.

\section{CONCLUSÃO}

Foi possível através da presente avaliação, concluir que o pó de Gesso Tipo IV depositado sobre uma impressão labial latente em substrato negro, foi capaz de tornar viável a sua evidenciação e passível de confronto queiloscópico.

\section{REFERÊNCIAS}

1. Stamm A, Carriego M, Irazábal S, Outes M. Diferencias Por Género A Través Del Estúdio De Los Tipos De Huellas Labiales Em Estudiantes: De Posgrado De La Facultad De Odontologia De La Universidad De Buenos Aires. Rev De La Fac De Odontol. 2019; 34(78):18-26.

2. Fallas Morales L, Corrales Solís AL, Fernández Chaves JM. Análisis De Huellas Labiales En Una Muestra De Estudiantes De Odontología De La Universidad De Costa Rica Mediante La Clasificación De Renaud: Estudio Piloto. Rev Med Leg De Cost Ric. 2018; 35(2):20-37.

3. Herrera LM, Fernandes CMS, Serra MC. Human Identification By Means Of Conventional And Digital Cheiloscopy: A Study Of The Literature. Rev Gaúc Odontol. 2013; 61(1):113-20.

4. Caldas I, Teixeira A, Pérez-Mongiovi D, Afonso A, Magalhães T. Identificação Por Queiloscopia E Palatoscopia. In: Corte-Real A, Vieira Dn, Organizadores. Identificação Em Medicina Dentária E Forense. Impr Da Univ De Coimbr; 2015. p. 109-31.

5. Barros GB, Silva M. Queiloscopia: Uso Da Técnica Na Identificação Forense. Diss (PósGraduação Em Odontol. Fac Odontol Da Univ SP, 2006. p. 160.

6. Fernandes LCC, Rabello PM, Santiago B. Queiloscopia: Um Método Odontológico De Identificação. In: Marques J, Aras W, Organizadores. Odontologia Legal: Coleção Tratado De Perícias Forenses. $1^{\circ}$ Ed. Leud; 2017. p. 250-82.

7. Suzuki K, Tsuchiahashi Y. A New Attempt Of Personal Identification By Means Of Lip Print. J Can Soc Foren Sci. 1971; 4(4):154-8.

8. Reddy LVK. Lip Prints: An Overview In Forensic Dentistry. J Adv Oral Res. 2011; 2(1):17-20.

9. Fernandes LCC, Cavalcante BGN, Oliveira JA, Santiago BM, Rabello PM. Validade Do Método Queiloscópico Utilizando Preceitos Dactiloscópicos Larissa. Uchôa C, Medeiros G, Organizadores. João Pessoa. Impressos: Gráfica Impressos Adilson; 2014. p. 364-371.

10. Chillagana KEP, Paucar BRC. Odontología Forense: Impresión Labial Y Fotografía Digital Para La Determinación De Sexo Y Raza En Estudiantes De Tercero De Bachillera General 


\section{RECIMA21 - REVISTA CIENTÍFICA MULTIDISCIPLINAR}

QUEILOSCOPIA: CASO PERICIAL SIMULADO EMPREGANDO EVIDENCIAÇÃO COM PÓ DE GESSO TIPO IV

Bruna Pasquali Nogueira, Lauren Volquind, Lucas Bozzetti Pigozzi, Mariá Bellan, Marília Paulus, Alexandre Conde

Unificado A,C Y D Del Colegio Menor Universidad Central. Graduação Em Odontol - Univ Cent Del Ecuador Fac Odontol Carr Odontol Quito; 2016. p. 96.

11. Chemello E. Ciência Forense: Impressões Digitais. Química Virtual; 2006. p. 1-11.

12. Coutinho CGV, Ferreira CA, Queiroz LR, Gomes LO, Silva UA. O Papel Do Odontolegista Nas Perícias Criminais. Rev Da Fac Odontol UPF. 2014; 18(2):217-23.

13. Peres AS, Peres S, Nishida CL, Grandizoli DK, Ribeiro IWJ, Gobbo LG, et al. Peritos E Perícias Em Odontologia. Rev Odontol Univ Cid SP. 2007; 19(3):320-4.

14. Corradi LM, Travassos DV, Coste SC, Moura RNV, Ferreira EFE. Identifying Missing People: The Contribution Of Forensic Dentistry And Dna. Rev Odontol Da Unesp. 2017; 46(6):313-8.

15. Dário LTP, Simões PW, Ceretta RA, Cechella BC, Bernardi AV. A Atuação Do Odontolegista Do Instituto Médico Legal De Florianópolis (SC) No Processo De Identificação Post Mortem. Rev Odontol Univ Cid SP. 2016; 28(1):17-23.

16. Araujo LG, Biancalana RC, Terada ASSD, Paranhos LR, Machado CEP, Silva RHA. A Identificação Humana De Vítimas De Desastres Em Massa: A Importância E O Papel Da Odontologia Legal. Rev Da Fac Odontol UPF. 2013; 18(2):224-9.

17. Fonseca GM, Ramírez-Lagos C, Ortiz-Contreras J, López-Lázaro S. Identificación Mediante Huellas Labiales: Casos Paradigmáticos, Oportunidades Perdidas Y "Anomalías" Para La Construcción De Un Nuevo Paradigma. Int J Odontost. 2018; 12(2):169-76.

18. Fernandes LCC, Soares ACM, Oliveira JA, Soriano EP, Santiago Bm, Rabello Pm. A Queiloscopia Na Identificação Humana: O Papel Da Calibração. Rev Bras Odontol Leg. 2017; 4(1):25-33.

19. Cartaxo LL, Pereira CP, Santos R. Identificação Médico-Legal De Uma População Portuguesa Através Da Queiloscopia. Diss (Mestrado Integr Em Med Dentária) - Univ Lisboa Fac Med Dent; 2015. p. 79.

20. Oliveira JA, Rabello PM, Fernandes LCC. Estudo Queiloscópico Em Graduandos De Odontologia. Pesqui Bras Odontopediatria Clin Integr. 2012; 12(4):521-8.

21. Stamm ADB. Propuesta De Nueva Clasificación De Huellas Labiales A Través De Estudio Preliminar Comparativo En Población Militar Argentina. Rev Bras Odontol Leg. 2014; 1(1):92103.

22. Lima MVFN, Costa GM, Silva VB, Nascimento MR, Moraes HH, Lucena EES. Verificação Da Praticabilidade E Da Unicidade Na Queiloscopia E Na Palatoscopia Como Métodos De Identificação Humana. Rev Bras Odontol Leg. 2016; 3(1):5-14.

23. Patiño, J; Patiño, E; Casas A. Giimub Linea De Investigacion En Informatica Medica: Queilosoft - Huellas Labiales. Rev Cient Fac Odontol Univ Bosque. 2005; (5):1-4.

24. Bernardoni M, Sauer S, Stamm ADB. Análisis Experimental Del Comportamiento De Huellas Labiales En Cadáveres Frescos Usando El Método Fraile. Gac Int Cienc Foren. 2013; (8):1624.

25. Fonseca G, Bonfigli E, Cantin M. Experimental Model Of Developing And Analysis Of Lip Prints In Atypical Surface: A Metallic Straw (Bombilla). J Forensic Dent Sci. 2014; 6(2):126. 


\section{RECIMA21 - REVISTA CIENTÍFICA MULTIDISCIPLINAR}

QUEILOSCOPIA: CASO PERICIAL SIMULADO EMPREGANDO EVIDENCIAÇÃO COM PÓ DE GESSO TIPO IV Bruna Pasquali Nogueira, Lauren Volquind, Lucas Bozzetti Pigozzi, Mariá Bellan, Marília Paulus, Alexandre Conde

26. Lucchese L, Fernandes MM, Conde A. Impressões Labiais Latentes Em Queiloscopia Forense: Caso Pericial Simulado Empregando Evidenciação Com Pó De Toner. Rev Brasi Odontol Leg. 2020; 12.

27. Andrade MM. Introdução À Metodologia do Trabalho Científico. $8^{\circ}$ ed. São Paulo: São Paulo: Atlas; 2007.

28. Silva AA, Dezem TU, Terada ASSD, Galo R, Silva RHA. Precisão na análise queiloscópica e seu potencial uso forense. Rev Bras Odontol Leg. 2020; 7(3):2-11. 